Educational Research for Social Change (ERSC)

Volume 7 No. 2, September 2018

pp. 39-56

ersc.nmmu.ac.za

ISSN: 2221-4070

\title{
Immigrant children's geographies of schooling experiences in South Africa $^{1}$
}

Sanam Isseri'

School of Education, University of KwaZulu-Natal

sanamisseri1@gmail.com

Nithi Muthukrishna

School of Education, University of KwaZulu-Natal

muthukri@ukzn.ac.za

Susan C. Philpott

School of Education, University of KwaZulu-Natal

PhilpottSue@gmail.com

\section{Abstract}

The aim of this research was to explore the schooling experiences of academically highfunctioning immigrant learners in the province of KwaZulu-Natal. The participants were six female immigrant learners (age range: $13-18$ years) in Grades 8 to 11. The research tradition was narrative inquiry. Data generation involved open-ended interviews and a participatory research technique, photovoice. The findings revealed the resiliency and agency of the young learners as they navigate schooling in South Africa. It was apparent that they took on a positive stance despite the struggles they have experienced in the host country, including language and cultural barriers, social isolation and exclusion, and bullying and discrimination that heightened their vulnerability in schooling spaces. The study revealed their strong sense of self-efficacy, responsibility and self-discipline, determination to succeed, commitment to their studies, and to make the best of valued opportunities in South Africa. Social capital emerged as a key protective influence that shaped the schooling experiences of the learners.

Keywords: Immigrant learners; South Africa; Children's geographies; Social capital; Photovoice

Copyright: (C 2018 Sanam Isseri, Nithi Muthukrishna \& Susan C. Philpott

This is an open access article distributed under the terms of the Creative Commons Attribution Non-Commercial License, which permits unrestricted non-commercial use, distribution, and reproduction in any medium, provided the original author and source are credited.

\footnotetext{
1 Ethical clearance number: HSS/0250/013.

2 This article draws on Isseri's M. Ed dissertation, The geographies of teaching and learning at a secondary school: Narratives of six high performing immigrants (Unpublished master's thesis). University of KwaZulu-Natal, South Africa. Anbanithi Muthukrishna supervised the dissertation and Susan Philpott assisted with data analysis and interpretation.
} 
Please reference as: Isseri, S., Muthukrishna, N. \& Philpott, S.C. (2018). Immigrant children's geographies of schooling experiences in South Africa. Educational Research for Social Change, 7(2), 39-56. http://dx.doi.org/10.17159/2221-4070/2018/v7i2a3

\section{Introduction}

South Africa has become today's economic centre of sub-Saharan Africa and the country has attracted a wide range of regional and international migrants seeking economic opportunities or freedom from oppression in anticipation of a better life (Vandeyar, 2012). The South African Constitution of 1996 and its Bill of Rights protects the rights of all children in the country-irrespective of whether they are children of immigrants or citizens. All children are entitled to education and have a right to quality education. The Refugee Act, passed in 1998, has been welcomed as a necessary piece of legislation that provides for the needs of forcibly displaced persons coming to South Africa in search of asylum (Republic of South Africa, 1998). It states that refugees are allowed to seek employment and to access education, as well as being entitled to the rights enshrined within Chapter 2 of the Constitution.

The increasing number of immigrant learners attending South African schools has inspired research into how children experience schooling spaces in the host country. Studies have shown that immigrant learners encounter many struggles in schooling contexts, including those related to language barriers, bureaucratic complexity, and difficulties with cultural and social integration (for example, Harju, 2018).

The issue of language in the context of curriculum access for immigrant children in host countries is a key theme in literature (for example, Calderon, Sánchez, \& Slavin, 2011). Research indicates that language difference is a key barrier that many immigrant children face in the new country (Bang, Suárez-Orozco, \& O'Connor, 2011). Findings suggest that the degree of proficiency in the dominant language of the host country may create opportunities for, or barriers to, acceptance and the building of friendships between immigrant and indigenous learners. Hornberger and Vaish (2008) explained that when immigrants leave their country, they leave behind their language and way of life in order to adapt to the new country. Thus, the indigenous languages of immigrants may be lost during the process of assimilating to a different country.

A common challenge that immigrant learners face is at the level of cultural and social integration. Studies have highlighted that this initial barrier may be attributed to a difference in culture and lifestyle. The degree of "belonging" within school cultures has been examined by researchers such as Maduray (2014), and Vandeyar and Vandeyar (2012). These studies suggested that the extent to which immigrant children feel a sense of belonging within a school setting and are able to identify with others shapes their identities and their acculturation to their new environment.

Research related to immigrant learners shows that they do experience difficulty in identifying with the curriculum content in schools (Ghong, Lychene, Larke, \& Webb-Johnson, 2007). Ghong et al. (2007) argued for the importance of a culturally responsive curriculum that uses the cultural characteristics, experiences, and perspectives of ethnically diverse students as conduits to teaching them more effectively. This argument is based on the assumption that when academic knowledge and skills are situated within lived experiences and frames of reference of students, they are personally meaningful, have higher interest appeal, and are learned more easily.

The experience of xenophobia and the intolerance of foreigners has been documented internationally both in societies and schooling contexts (for example, Adjai \& Lazaridis, 2013). The biological-cultural features of hairstyles, accents, vaccination marks, dress, and physical appearance signify difference and play a role in prompting racist actions. Adjai and Lazaradis (2013) explained that biological-cultural markers are significant in generating xenophobia and racism because they point out whom to target. 
Research has shown that while many immigrant families and their children face multiple risk factors, they bring with them a number of characteristics that serve as protective factors, including religious beliefs, a sense of community, optimism, determination to succeed, and an appreciation of educational opportunities in the host country (Vandeyar, 2012). The emergence of "cultural capital" as a contributing influence that enables immigrant learners to succeed in the face of demands of assimilating into a foreign country has been documented in research (Lee, 2011). Further, researchers have highlighted social capital as an explanation for the academic achievement of immigrant children (Heywood \& Peterson, 2007). In essence, social capital is conceptualised as the resources children access through shared and flexible interactions, relationships, and networks.

The concepts of care and caring, in the context of schooling, emerged in research on the resiliency of immigrant children (Lalas \& Valle, 2007). A study by Naiditch (2013) indicated that caring in a school is about creating positive social relationships and a welcoming school culture and ethos. In a multicultural school context, research suggests that there should be high levels of interest in, and affirmation of, students' cultures, languages, customs, and values to create a welcoming school climate for learners and parents (Heywood \& Peterson, 2007).

In reviewing literature on the schooling experiences of immigrant children, much of the research focuses on the pressures learners face in schools. Sidhu and Taylor (2012) pointed to the fact that research on refugee children tends to focus on their struggles in the host country and constructs them as vulnerable and in distress. This impedes an authentic analysis of their identities, and how they navigate schooling. In order to address this concern, this study examined the schooling lives of academically high-functioning immigrant learners with the hope that it would illuminate their agency and resiliency as well as how they negotiate the vulnerabilities they may face. The research questions were: What are the schooling experiences of high-functioning immigrant children in South Africa? How do they navigate inclusionary and exclusionary spaces in their lives? What stories do they have to tell about their experiences of care and caring in their schooling lives?

\section{Theoretical Framing}

The paradigm in childhood studies referred to as New Sociology of Childhood (NSC), and the sub-field of Children's Geographies informed the theoretical framing of the study. Children's geographies is an area of study within human geography that studies the spaces and places of children's lives (Tucker \& Matthews, 2001). The view is that children's lives will be experienced in diverse ways in varying times, places, and spaces, and in diverse circumstances. Scholars in the field argue that the spaces in children's lives are often power laden, and the myriad of ways this power plays out is of vital scholarly importance and needs to be explored by researchers (Van Ingen \& Halas, 2006). Critical questions about schooling contexts may be: Whose culture and language is affirmed? Who is in? Who is out?

The concept of New Childhood Studies started to emerge in the early 1980s and 1990s during which time, the role of children as active agents of change emerged in debates (Punch \& Tisdall, 2012). Within traditional conceptions that have drawn heavily from the discipline of psychology, children had been viewed as being immature, adults in the making, powerless, and unable to make concrete decisions by themselves. However, in the last three decades or so, this frame of thought has changed to focus on the child, rather than viewing the adult as the sole decision-maker in the lives of children. This line of thinking aligns with the revolutionary United Nations Convention on Rights of the Child (United Nations, 1989), which brought childhood to the forefront of international political and academic debate (Bisht, 2008). From this perspective, it is argued that children should be perceived as social actors who have views about issues and agency in the spaces in which they interact (Punch \& Tisdall, 2012). In the study presented in this article, innovative data generation methods were used to elicit, 
listen to the voices of the child participants, and examine the spatial, experiential, emotional, and ethical dimensions of their lives.

\section{Research Methodology and Design}

The study was qualitative in nature, allowing for an in-depth understanding of the phenomenon under investigation, namely, academically high-functioning immigrant learners' experiences of schooling in their host country. The research tradition was narrative inquiry. This was an appropriate way to gather data about lived experience because it allows for a story or narrative to be told (Kramp, 2004). There are four main processes whereby participants are encouraged to share their stories and life experiences: living, telling, retelling, and reliving (Clandinin \& Connelly, 2006). In the study, participants were involved in retelling stories about their experiences of schooling as academically high-achieving immigrant learners at a South African school.

The view taken by the researchers in this study was that narratives or stories are made in context and in social interaction. The aim was to gain an understanding of participants' attribution of meanings of their experiences and actions. The focus was on meanings and perceived realities rather than facts. The position taken was that knowledge and information is constantly being created, developed, and redeveloped by reflective and feeling individuals in context and in social interaction. Further, stories often illuminate relations of power and power dynamics in context; such workings of power cannot be ignored because they have a profound impact on the individual as well as the collective.

\section{Research site and participants}

The study was conducted at a girls-only, secondary school in central Durban, in the province of KwaZulu-Natal, South Africa. The site was selected purposefully because the enrolment of foreign learners had increased over the past few years. After a review of literature (for example, Haskins \& Tienda, 2011; Schuster, 2012), the term immigrant learners was defined as children from foreign nations who had settled in South Africa, and were learners in South African schools. Their families may have been legal or illegal immigrants, refugees, asylum seekers, or migrant workers.

Six learners were selected purposefully for participation in the study. The learners identified were foreign nationals who were high functioning academically. Their scores in the various school subjects in the mid-year tests reflected a grade average of $65 \%$ and above. They were aged between 13 and 18 years and in Grades 8 to 11.

\section{Data generation and analysis}

The key data production technique was the narrative interview, characterised by flexibility and nonrestricted questioning. The focus was on foregrounding narratives (stories), facilitating the relating of stories and experiences, as well as making meanings of their different social constructions of their schooling realities (Pinnegar \& Danes, 2007). Interviews were in the form of natural flowing conversations, allowing the researcher and the individual participant to develop the story through an interactive process (Phillion, 2002). The narrative interview question was: Tell me the story of your schooling experiences in South Africa? The interview process ensured that participants reconstructed their schooling experiences as everyday communication of telling and listening to stories, with minimal intrusion from the interviewer.

An innovative "edge" was added to the study in the form of an interactive, participatory research tool-photovoice. With the intention of enabling the children's voices to be heard, photovoice seeks to place children at the centre of the research process in contrast to many traditional research methods 
led by primarily the researcher. Developed by Wang and Burris (1997), this is a methodological variant of photography as a visual technique of data collection (Kembhavi \& Wirz, 2009). Photovoice allows participants to visually document experiences, which provides them with the basis on which to engage in dialogue around issues. Photovoice is a technique that lends itself to active participation in research by the participants, enabling them to freely capture their experiences via a series of photo images. In this study, participants were given disposable cameras and requested to take photos that would convey the story of their schooling lives, past and present. The photovoice method and process used is outlined in Isseri (2016). Photovoice generated photo narratives that augmented and enriched the stories that emerged in the open-ended interviews.

Interviews were conducted in English. All participants were proficient in English to the extent that they were able to engage in an everyday communication process of telling stories. In narrative inquiry, stories emerge from the interaction and dialogue between interviewer and participants. The interviewer was very aware of the critical importance of aligning with and using the spontaneous language of the participants without imposing her own language. Interviews were digitally recorded and later transcribed.

In the first stage of photovoice data analysis, the photographs and related data from participant comments and discussions were collated, studied, and shared by the first and second authors. The following questions were engaged with jointly: What does the photograph depict? How does it relate to context? How does it relate to the issue of schooling experiences? What is spoken? What is not spoken? How does the photo narrative compare with the particular visual representation?

In the second stage, the narratives from the photovoice method and open-ended interviews were read and reread a number of times to gain an in-depth understanding of how they depicted participants' schooling experiences. Data analysis was an inductive process: identifying broad categories of constructs and issues, drawing on the literature review and theory to make sense of trends, and identifying patterns and themes.

Various ethical issues were considered during the research process. Permission from the KwaZuluNatal Department of Education and the school principal was secured. Informed assent was obtained from the participants. Due to the participants being legally minors, informed consent was obtained from their parents or guardians. The participants were assured of anonymity and confidentiality in respect of their narratives.

\section{Trustworthiness}

To ensure credibility of the research, clear and detailed description of how data was generated and what counted as data is provided. To ensure transcription accuracy, the first author accessed the assistance of a critical friend to check whether the recorded data was accurately captured in the transcriptions. Further, the transcribed data were taken back to the participants to verify and clarify particular issues raised, wherever necessary. During the data analysis process, the researchers engaged in the process of verification of emerging categories, themes, inferences, and theoretical interpretations, using a method of constant comparison. In order to assist other researchers to ascertain the transferability of the study to other contexts, a detailed account of the research methodology and design and the design choices made in the study is provided in this article. The study utilised two different data generation methods, namely, photovoice and the narrative interview to elicit different constructions of reality. 


\section{Discussion of Findings}

How immigrant children experience schooling spaces is critical to the development of their identities and their transition to and integration into the culture of the school. Van Ingen and Halas (2006) have argued that schooling spaces are where values, ideologies, and practices intersect. The key findings in the study are discussed below.

\section{Tensions within schooling experiences}

In South Africa, the principles of inclusion, equity, and social justice for all are embedded in education legislation and policy frameworks such as the South African Schools Act of 1996 and Education White Paper 6 (Department of Education, 2001). These frameworks enshrine the rights of all children to quality education, to a schooling context free of discrimination and exclusion, irrespective of diversity on the basis of race, class, national origin, gender, or other differences. Section 28(3) of the Constitution of 1996 protects the rights of all children, including immigrant children, and gives protection to children's rights whilst the Children's Act of 2005 gives effect to these rights. Legislation affirms that every child has to be protected from maltreatment, neglect, abuse, or degradation.

In exploring the question of how the participants experienced schooling, the study revealed that the immigrant learners often encountered forms of oppression, vulnerability, and marginalisation. Participants' narratives provided insight into struggles they experienced in ethically and emotionally challenging and exclusionary spaces. Critical incidents recounted by participants reflect how social relations shaped and constructed particular spaces. Space also shaped and produced particular social relations (McGregor, 2004).

Five out of the six immigrant learners reported being bullied on the basis of their nationality, language, culture, accent, and physical appearance and encountering negative stereotyping. Nansel et al. (2001) defined bullying as a specific type of aggression in which behaviour is intended to harm or disturb, the behaviour occurs repeatedly over time, and there is an imbalance of power with a more powerful person or group attacking a less powerful one. Susan ${ }^{3}$ narrated the various kinds of harassment she suffered in the schooling context, often linked to personal characteristics.

I lost my colouring pencils, and when I asked who took them, everyone was acting as if they did not know and when I noticed it in someone else's bag and when I accused them, they started calling me all sorts of names.

The study shows that many of the incidents of bullying experienced by the participants had xenophobic undertones, reflecting a dislike of foreign nationals. Tina stated that she experienced discrimination in the schooling context due to her traditional Congolese hairstyle. The following extract illustrates her experience with a learner in her class.

I think he was laughing at me because of my hairstyle. It was a normal hairstyle from where I come from.... It is a thing that most kids in Congo do.

Discriminatory attitudes related to their home languages were reported by three of the six participants. Often, the isizulu language, the mother tongue for most children in the province of KwaZulu-Natal, dominated informal social spaces - a language of which the immigrant children had no knowledge. Barriers to language and communication have been identified as a major challenge that most immigrant learners face in host countries (Kamaungu, 2007). All six participants in the study

\footnotetext{
${ }^{3}$ Pseudonyms are used to protect the identity of all the participants.
} 
experienced language and communication barriers when they first arrived in South Africa. Even though South Africa is a diverse nation, the English language dominates in many teaching and learning contexts. Tina explained that she often felt excluded and marginalised in social spaces, and how such experiences caused anguish and distress to her.

I did have South African friends in Grades 6 and 7. They will always speak Zulu around you and when you ask them to explain what they said, they would say, "Aah, never mind." In class they will make a joke in Zulu and you are the only one that will be lost and they all will be laughing.

Similarly, Susan recalled,

If you ask them what they said, they will carry on ignoring you and laughing, they won't tell you what it is all about. It makes me feel bad because I feel left out.

All six participants reported that they experienced discriminatory attitudes from learners who did not approve of them speaking their own home language at school. Tina and Ruth explained that if they conversed in Swahili, the dominant group of South African learners would request them to discontinue the conversation. Greene (2012) reported similar findings in her study that examined the personal narratives of Latino adolescents in the USA. They made mention of social and political stigma linked to the use of Spanish outside of the family and Latino community. The participants spoke of negative attitudes of non-Spanish peers and certain teachers who banned use of their home languages at school. Ruth explained,

I remember once, it was here at this school in Grade 9 and we were sitting, and I was talking to my friend in class, and then one of the South African learners stood up and said, "Don't speak your language here." We were talking in Swahili.

Tina explained that often the immigrant learners would translate aspects of conversation from their language into English to keep South African learners included in social groups. Tina pointed out that the dominant group never translated isizulu into English for them. She explained, "for example, one of the foreign girls speaks in Lingala and we translate it to them, but they never translate for us." The narratives reflect that a discourse of domination operates alongside a discourse of respect and recognition. Such spaces were emotionally testing for the participants who were fully aware of the political stigma attached to their home languages but remained proud of their languages. Michelle poignantly explained she viewed her multilingual abilities as an asset. She could speak French, English, and Lingala.

One participant spoke of her experiences of discriminatory attitudes related to language that emanated from a teacher. Reflecting on her experience in a complex socioethical space, Ruth narrated this.

My social science teacher was speaking in Zulu, and I could understand a bit, but then the boy behind me who was a refugee like me, could not understand, so then he put up his hand and said, "English please Mam," and the teacher asked, "Who said that?" Everyone pointed at him and the teacher said, "This is South Africa and Zulu is the first language and if you do not understand, go back to your country. We didn't call you to come here." 
Without doubt, the teacher implicated in this critical incident is complicit in violating the human rights of immigrant learners embedded in South African policy and legislation. She also perpetuates a social milieu that legitimises intolerance of diversity in respect of racial, ethnic, and cultural differences. Such a space in which a teacher is complicit in oppression is likely to be ethically challenging to immigrant learners who are aware that such behaviour is not justifiable on moral and ethical grounds, and from a rights agenda. What is concerning here is that the learners involved in this critical incident had no pastoral care structures in the school to which they could turn to seek help and support or to challenge the actions and actors. The silences around such spaces and the meanings they generate allow them to continue producing and reproducing discriminatory practices and sustaining unequal power relations and oppression.

\section{Navigating inclusionary and exclusionary spaces}

The study examined how the participants negotiated social spaces of inclusion, exclusion, identity, and belonging. Through their narratives, the participants revealed who they are, the subject positons they take, and how they are positioned by others socially and spatially.

The participants adopted their own socio-spatial strategies to engage in spaces of oppression as intentional beings. At times, they simply ignored comments and walked away. Thus, the general approach amongst the participants was an acceptance of the oppression, and the adoption of the view that "life has to go on." For them, their key focus was on their studies and on performing well in school. Ruth explained, "Sometimes you can do something about it, but other times it is better to just walk away." There were learners who despite their often critical and reflexive engagement with issues evident in the interviews, intimated that they "understood" the positioning of the South African learners, and chose to ignore such incidents. The ethical questions these narratives raise are: Does not such a strategy, that justifies discrimination by accepting the existing order of social relations as given, perpetuate and entrench oppression and otherness? Is the strategy of resistance too complex for these young learners who are constructed as the other? Is the life-goes-on strategy acceptable in a country and education system that has committed to principles of nondiscrimination, inclusion, and social justice? Is the education system failing these learners by not creating schools that are safe, welcoming, inclusive spaces where all learners are affirmed and respected, whatever their histories and backgrounds?

Tina explained how her mother has helped her deal with discrimination and navigate adversity-a strategy that has strong religious links.

My mum always says that I should not worry about what other people say and I should not hold grudges. I should forgive them because God is watching them. It is better to forgive than hold a grudge because at the end of the day you feel better.

In the photovoice activity, Tina shared a photograph of her mother.

This is my mum. She inspires me a lot. She always tells me to never give up. She is a cleaner at Hyundai. She always encourages me and tells me even though there is discrimination, try to be friends with those who discriminate.

In analysing how the participants navigated their schooling spaces, a key theme that emerged was that of resiliency and agency within spaces of oppression. The term resilient can be used to describe individuals who have the initiative to flourish and make a difference in their environments despite the challenges they may face (Ramirez, 2007). Seror, Chen, and Gundersen (2005) highlighted various features of resilience such as problem solving, cultural belief in the value of education, social 
competence, satisfaction with school, and family support. They further stated that educational resilience is about a high likelihood of success in school despite adversities brought about by situated conditions.

Research in Spain on immigrant learners' drive to succeed by Esteban and Marti (2014) showed that even learners from disadvantaged communities can develop unique strategies and attitudes to enable academic success. For example, students who had high academic self-concept were shown to have a high degree of resilience. The researchers argued that the ability to resist adverse situations associated with academic dropout may be related to the learners' social environment, such as support from family, good role models, and personal networks that build social capital and reduce vulnerability (Esteban \& Marti, 2014). Our study indicated that a key influence that shapes the academic achievement of immigrant children is the drive and determination of both parents and children to succeed in the host country (as found in other studies internationally, for example, Gunderson, D'Silva, \& Odo, 2012).

In the study, having immigrant role models was important to the participants. They indicated that they were inspired by other academically high-functioning immigrant learners. The narratives revealed this influence that shaped their resiliency in the face of adverse experiences. Ruth explained,

I think I found other refugees in the country that spoke English, and when I came here I did not know how to. The other refugees motivated me by speaking English because they spoke it so nicely. Their fluency motivated me. I also used to read a lot.

The participants showed that they had a high level of competitiveness and drive to be top students in the school. Furthermore, a school environment that affirmed and rewarded high academic performance was an important factor in their growth as students. Other high achieving learners in the class influenced immigrant learners tremendously, thereby contributing to their own success.

I looked at people and saw that other people were getting trophies and I also wanted to get those trophies. In Grade 6, I told myself that I needed to work harder. So I worked hard and got my Dux in Grade 7; I got awards for English, math and other subjects, except for Afrikaans. (Ayesha)

All six participants were very appreciative of the opportunity to study in South Africa-a country that they viewed as having a better education and health system than their home countries. Jane explained,

I have been here for seven years and it has been a good experience because it is better than my country because I could learn and get a better education, not like other people, who did not get a better education or died because of the war or there was no health care.

Participants showed that they are intrinsically motivated to perform well academically and that they had clear goals and aspirations. Without doubt, they were goal driven and seemed to have high levels of self-efficacy. Tina explained how her low grades in her last math exam spurred her to aim higher and overcome the difficulties she was experiencing in the subject. Her study strategies were selfinitiated and reflected her agency.

My results were always top but in Grade 6, I think in the third term, I dropped a little in math. I think I got a two in math, and I was very disappointed and that was what pushed me to actually work hard. That is why my marks always used to stay at the top. 
The voices of the participants showed their resiliency and agency despite the struggles they faced. Seror et al. (2005) argued that resilient children are more satisfied with, and have more positive views of, their schooling. As in the present study, Seror et al. (2005) found that resilient learners believe that success depends on hard work, strict discipline, and determination. The learners' strength of character, their determination, and resolve as they navigated various challenges provided insight into their agency. Mashford-Scott and Church (2011) explained that important elements of agency are selfefficacy, resilience, a sense of self-worth, and the ability to take a reflexive stance and make considered choices-qualities evident in the participants in the study.

\section{The spatiality of care and caring}

The study provided insight into the spaces of care and caring in their schooling experience through the lens of the immigrant learners. It illuminated the social production of care and caring and the meaning of this space. Various socio-spatial relations and practices defined how care and caring are experienced by the participants. In other words, the spaces of care are produced through the social. The research drew on the notions of caring about and caring for from Noddings (1992), where caring for involves everyday interpersonal relationships, such as a teacher inquiring about a learner's emotional wellbeing or listening to her learners. A parent may care for the academic progress of her child and may ask the child whether she needs assistance with an assignment or project or having high expectations for her child. Caring for is generally private, and happens within interpersonal relationships, and in specific situations. The act of caring about implies that it is wider than any one interpersonal relationship. Caring about can be related to communities of practice such as a school where particular beliefs, values, and cultures play out (McKamey, 2011). An example is caring about test scores, the adequacy of learning teaching materials, or the school curriculum. The key socio-spatial contexts of care, social relations, and practices are examined below.

\section{The family}

The study examined how caring is produced, and plays out, in the lives of the participants. In the case of all six participants, family support and the ethics of care were very strong. There was evidence of caring about and caring for. Caring about was related to the school curriculum and parents, siblings, and relatives caring about curriculum access for the participants, for example, language access and obtaining good grades in school tests and examinations. In caring for, the focus was on interrelationships and individual wellbeing. Parents in particular played a significant role in building self-esteem, motivation, and drive in their children. The narratives of Tina and Jane illuminate the spaces of care and caring in their lives.

My dad says that I should focus on my studies, and I should not feel low about myself and must encourage myself to do better the next time. He says that it is my life and I should decide what is good for me and what is not. (Tina)

My brother has really helped and guided me throughout school. He started his schooling here in South Africa and he is now in Grade 9. He is my role model because he would get high marks. He even received awards in Grade 1 and 2 for having the highest marks in English. (Jane)

Tina's photovoice discussion indicated that she saw her sister who was studying at a tertiary institution as a role model who had a tremendous drive to succeed. The study revealed that a strong family support system and an ethics of care from family members heightened the participants' agency and their competence in taking responsibility for their studies, suggesting that agency is relational in nature rather than individual action. The family is a safe, nurturing, and protective space for the six participants where the social process of identity formation takes place. Bartos (2012) argued that while 
many studies on children's agency focus on the building of independence and individualisation, it is crucial to take into account that the social and political practices through which culture is produced are significantly social in nature. She argued that agency may be dependent more on relationships rather than personal autonomy.

\section{The school}

The culture and ethos of the school is key to creating an inclusive, welcoming school context for all learners irrespective of difference. School leadership and teachers are critical to the process of building a positive school climate characterised by mutual respect for the rights of everyone, the valuing and appreciation of diversity, and a deep understanding of difference. Participants indicated that certain caring teachers with whom they interacted played a significant role in their lives, particularly in helping them to integrate into the South African schooling context. Ruth made special mention of her English teacher in Grade 2 who "went the extra mile" to help her develop her competence in reading, and by being responsive to her individual needs.

In Grade 2, my teacher supported me the most because at that time reading was a problem for me. She used to stay back after school and teach me words one by one and then she would write a sentence. She would give me reading books to take home. It helped me a lot.

Jane alluded to the fact that one of her teachers contributed to her strong sense of self-efficacy and her self-confidence.

One of the teachers who motivated me is Mrs S, because she told me that I can be anyone that I want to be, whether you are a boy or girl, you can achieve your goals.

Ayesha described how a teacher enabled her to learn, understand and speak the English language fluently. With her help and translation of the language, Ayesha claimed she was able to adapt to her new environment faster and more easily:

I think my biggest inspiration in primary school is Mrs B. Even up till now, I still look up to her and thank her. I think she is the one who has made a big impact on my life. I could not speak English. I could only go to her, not any other teacher, because she knew Hindi.

Ayesha explained that it was through caring and supportive teachers like Mrs B. she was able to excel in school and realise her academic goals. Image 1 is a photo of a poster that Ayesha captured to depict the role Mrs B. played in her schooling life. 
Image 1: Ayesha's poster-Ayesha's Inspiration

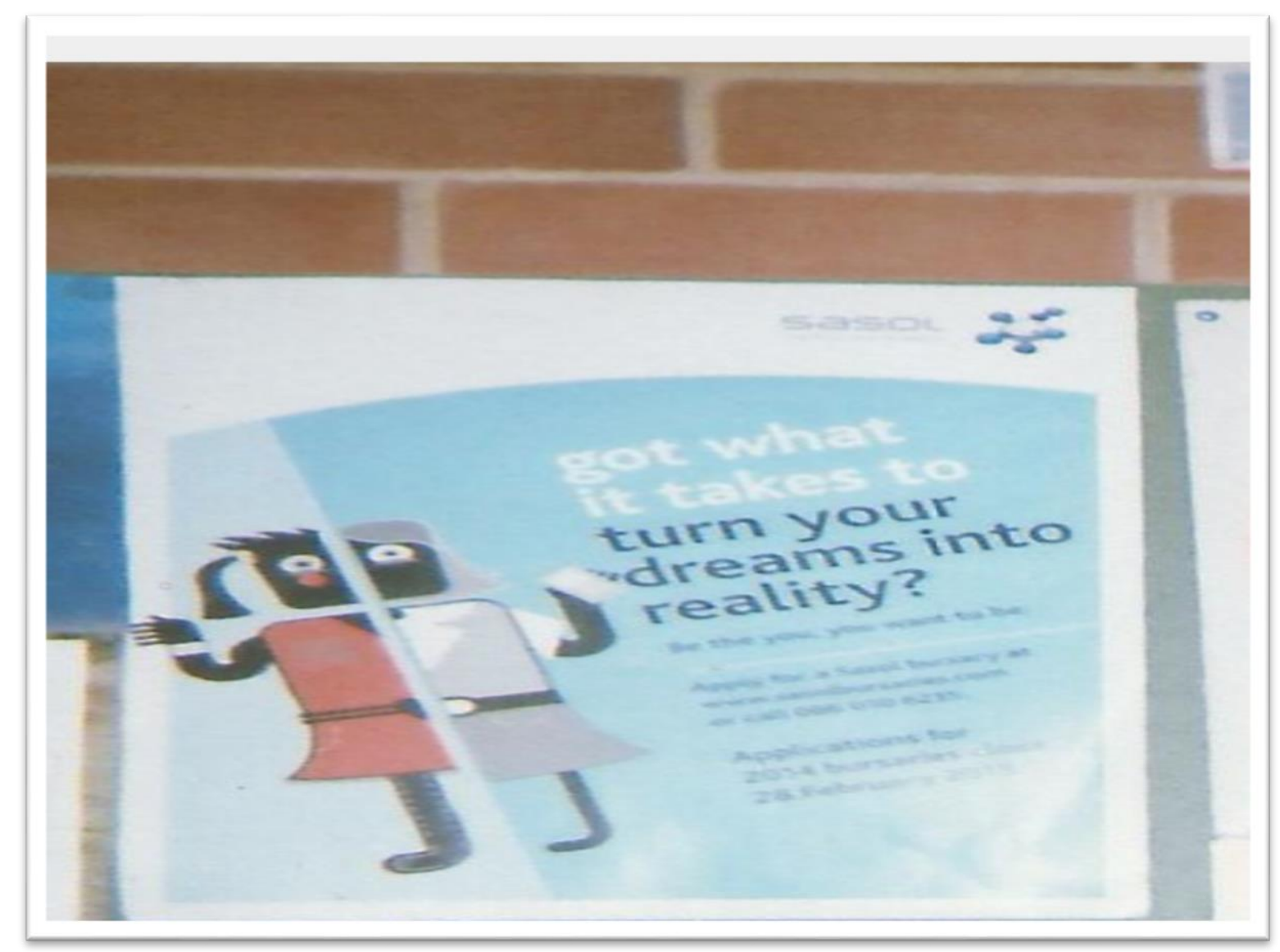

Lumpkin (2007) argued that teachers who care and believe in their learners' abilities place learners at the centre of the educational process. The acts of care by the teachers in the above narratives suggest that care is about equitable access to the curriculum for all their learners and about children's resiliency and wellbeing. The study raises certain questions about care and caring: Why do particular teachers care, and others perpetuate oppression? Are there conditions that enhance the possibility of care? Who are the care subjects, and how and why are they the recipients? What are the limits of care and caring?

\section{Social networks}

The findings revealed that the participants valued social networks or the social capital that they were able to access. The learners have been able to accumulate and use social capital to their benefit, and create their own spaces of inclusion and belonging. The study showed that the participants were building social capital through friends and friendship groups, religious institutions, and immigrant support groups. They are very aware of the value of building social capital and applying effort to sustain and maintain social networks. Capparelli's (2013) research on immigrant students revealed that social capital is an important factor in determining the success and social wellbeing. The present study also showed that networks are a social and emotional asset to the learners in the complex and often demanding social space of the school. Michelle valued the network of friends in her life.

My friends inspire me in some way, when I feel down, they always do things to cheer me up. We have the best time together. We just talk about anything that makes us happy. We share ideas and opinions on what we think about something. 


\section{Religious affiliations}

Three of the six participants in the study spoke of the impact of religion as an institution in their lives. Michelle explained that the Bible is her inspiration, and her religion gives her hope and the confidence to overcome obstacles. For the photovoice task, she took a picture of her Bible (Image 2).

This is a picture of the Bible. It gives strength. In life, there are times that you feel that there is no hope, like last year when my maths mark was not improving. There are always some inspiring words from the Bible that renew my strength.

\section{Image 2: Michelle's source of hope-the Bible}

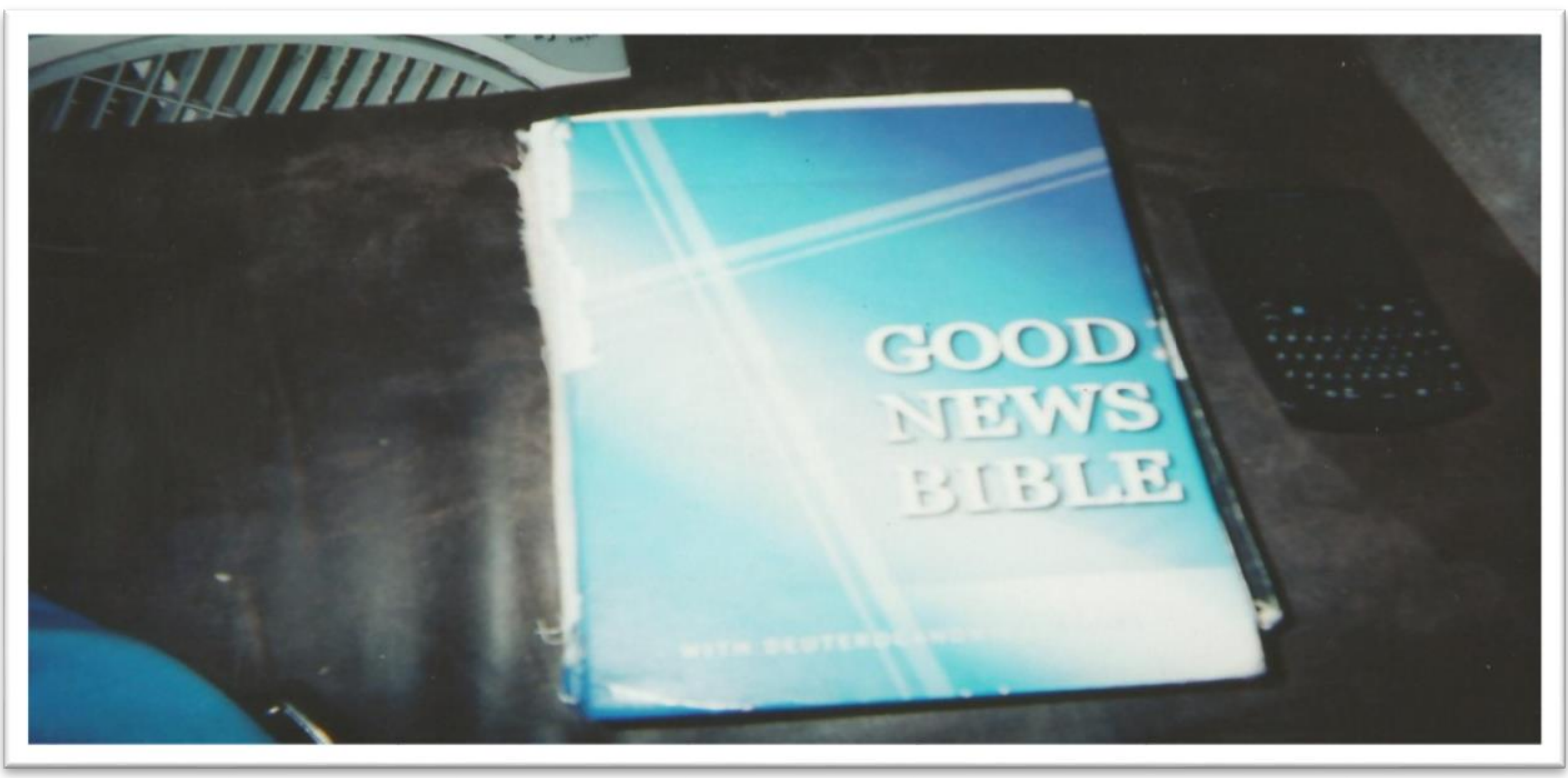

Tina's church support group is a key source of social capital in her life, encompassing empathy and a sense of belonging. She explained that the members supported her and her family emotionally during difficult phases of her life.

Well, the pastor and all the members of the church care, like when my grandmother died, the church members came together, they visited, and also prayed for us for about one week. With regards to my schooling, for example, if my dad could not make it for school meetings, our pastor would come and he would take the role of my dad.

Image 3 depicts a photo of the T-shirts worn by members of the support group as an emblem that built a sense of community around their faith. 
Image 3: Tina's artefact-the support group T-shirts

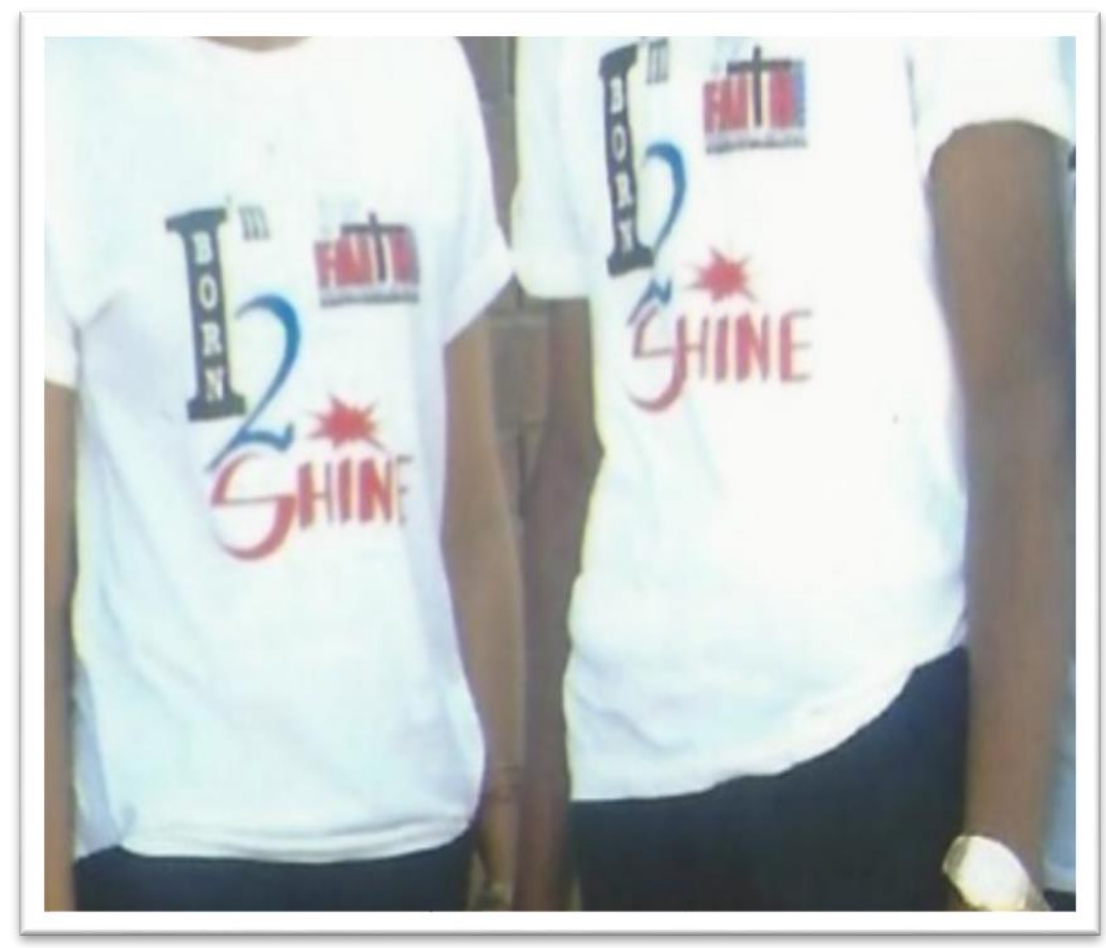

Research indicates that immigrant learners find it difficult to form networks or build social capital involving learners from the host country due to differences in cultural practices and language (Maduray, 2014). Studies have also shown that immigrant learners are more comfortable emotionally and socially around other immigrant learners because they were able to share their challenges and support one another (Ergul, 2012). A similar trend reflecting certain socio-spatial complexities was evident in the study presented in this article.

Most learners indicated that they felt comfortable in networks and friendship groups with other foreign students at their school. Four of the six participants indicated that they seem to have a closer bond with peers from other African countries. This does not concur with Vandeyar's (2012) research that found immigrant learners to have developed a continental identity to try and fit in with the South African environment. The present study showed that the participants were more aligned to an immigrant African identity. It seems that they have determined that since they do not fit in with the dominant group, distancing themselves and creating exclusionary boundaries of friendship is a way to claim their own social space. This raises the question of whether through such a spatial practice of friendship, these groups are positioned at the margins in the schooling context thereby reinforcing difference and otherness. It is evident from the narratives that these social groups share a tremendous pride in their cultural norms and values, immigrant social networks, and languages. Thus, these friendships groups are contributing to shaping the individual and collective identities of the learners, and are significant emotional and social capital resources.

\section{Conclusion}

This study sought to explore immigrant children's geographies of their schooling experiences in South Africa. Located within the paradigm of new sociology of childhood (NSC), children are viewed as social actors in the places and spaces of their everyday lives. Although much research has been undertaken on the experiences of immigrant learners at South African schools, as well as the struggles that they 
encounter (for example, Adebanji, Hartell, \& Phatudi, 2014), limited research has focused on the experiences of academically high-functioning immigrant learners.

In exploring the spaces and places of the children's schooling experiences, the study illuminated concerning issues of social exclusion, and oppression experienced by the participants from their peers and certain teachers. The kind of oppression the participants shared is unacceptable and indefensible, and goes against the principles of social justice, nondiscrimination and inclusion embedded in the South African Constitution and various education policy documents. Gunderson et al. (2012) reminded us that schools are "social institutions" containing "micro-societies" (p. 153). It is imperative that all those in leadership build a school climate and ethos of respect, acceptance of diversity, and inclusion, where the rights of all learners are upheld and protected. The issue for immigrant learners should not be about how to circumvent oppression in their schooling lives as was evident in the study. The question has to be about how the school and its leadership can foster positive racial and ethnic identities for all its learners whatever social groups they come from.

In examining how the immigrant learners in the study navigate their schooling experiences, the findings illuminated their agency, strong sense of self-efficacy, self-discipline, resiliency, determination to succeed and commitment to their studies, and making the best of valued opportunities in South Africa. They have a strong sense of pride in their culture, language, and ethnic background. They are proud of their multilingual competences and see this as an asset despite being aware of the political stigma attached to their home languages by peers in school. However, an important facet is that the participants have strong family support systems underlined by an ethic of care from family members and role models. The family is a safe, empathic, and protective space for the six participants where identity formation is nurtured.

An important finding in the study is related to the social networks in the learners' everyday lives that shape their schooling experiences. Leonard (2005) stated that social capital does not feature much in the work of scholars in the field of childhood studies. The study illuminated the networks that support the academically high-functioning learners socially, emotionally, and academically, for example, parents, family members, friends, youth groups. Leonard (2005) contended that the family is a central site of social capital. The study also illuminated the agency and resourcefulness of the learners as they accessed and sustained the various networks of social capital in their everyday lives. However, in line with the contention by Leonard (2005) and Bankston and Zhou (2002), the point to be made is that the study findings suggest that it is likely that the kind of social capital the learners have accumulated is effective because it is reinforced and sustained by other forms of capital, such as support from parents and family: well-connected family ties supported by the wider immigrant community and the economic and social resources available to the family. Zhou and Kim (2006) explain that an important policy implication may be that the public school alone may not be adequate to ensure immigrant learners' academic success.

A contribution of the study is the use of narrative inquiry in the exploration of caring, and the possible value of using this method given that care and caring are contextual in nature with varied dimensions. The use of narrative methodology in the exploration of caring is particularly relevant because it has the advantage of focusing on the participants' unique stories, which for them are real and authentic, without requesting them to think in decontextualised ways (McCance, McKenna, \& Boore, 2001); merely posing general questions, seeking opinions and views, or using a questionnaire to examine care and caring could be problematic, according to these researchers. However, it is conceded that acts of care are always located in complex politics and asymmetrical power relations may be involved in caring relations (Bartos, 2012). There are dynamics of power and questions of how power circulates in sites of care and this theme would push the study towards a critical paradigm. It is therefore an area for 
further research in which questions may be raised about how to unsettle notions of care such as: Care for 'for whom? "Who cares?" "What for?" "Why do 'we' care?" "How to care?" "What are the sites of care and caring?" (Martin, Myers, \& Viseu, 2015, p. 2).

The study also raises issues that can be explored further in future research in different settings. The significance of, access to, and use of social capital in the lives of immigrant children in schooling contexts in host countries is an area for deeper exploration, as is research on the notion of social capital which involves children. In addition, the patterns of resilience evident in high-functioning immigrant children in different contexts is a topic for further research.

\section{References}

Adebanji, O. T., Hartell, C. G., \& Phatudi, N. C. (2014). Factors facilitating the adjustment of immigrant children from Zimbabwe in the foundation phase to South African schools. Mediterranean Journal of Social Science, 5(3), 512-522.

Adjai, C., \& Lazaridis, G. (2013). Migration, xenophobia and new racism in post-Apartheid South Africa. International Journal of Social Science Studies, 1(1), 192-205.

Bang, H. J., Suárez-Orozco, C., \& O'Connor, E. (2011). Immigrant students' homework: Ecological perspective on facilitators and impediments to task completion. American Journal of Education, 118(1), 25-55.

Bankston, C. L., \& Zhou, M. (2002). Social capital and immigrant children's achievement. Research in the Sociology of Education, 13(1), 13-39.

Bartos, A. E. (2012). Children caring for their worlds: The politics of care and childhood. Political Geography, 31, 157-166.

Bisht, R. (2008). Who is a child? The adults' perspective within adult-child relationships in India. Interpersona, 2(2), 151-172.

Calderón, M., Sánchez, M., \& Slavin, R. (2011). Effective instruction for English learners. The Future of Children, 21(1), 103-127.

Capparelli, E. (2013). Can education help immigrant students gain capital? (Master's thesis). Retrieved from https://trace.tennessee.edu/cgi/viewcontent.cgi?referer=https://www.google.com/\&httpsredir= 1 \&article $=2720 \&$ context $=$ utk gradthes

Clandinin, D. J., \& Conelly, E. M. (2006). Narrative inquiry: Handbook of complementary methods in education research. Mahwah, USA: Lawrence Erlbaum.

Department of Education. (2001). Education White Paper 6: Special needs education: Building an inclusive education and training system. Pretoria, South Africa: Government Printers.

Ergul, A. (2012). The relationship between home and school literacies of a selection of Turkish immigrant children living in South Africa. (Unpublished master's dissertation). University of Johannesburg, South Africa.

Esteban, M. P. S., \& Marti, A. S. (2014). Beyond compulsory schooling: Resilience and academic success of immigrant youth. Procedia Social and Behavioural Sciences, 132(1), 19-24.

Ghong, M., Lychene, S., Larke, P. J., \& Webb-Johnson, G. (2007). Teach my child, too: African immigrant parents and multicultural educators sharing culturally responsive teaching tips. Journal of Praxis in Multicultural Education, 2(1), 61-69. 
Greene, M. C. S. (2012). The power of personal narrative: Latina adolescent youth in a third spaceimagined community. ITJ, 9(1), 7-15.

Gunderson, L., D'Silva, R., \& Odo, D. M. (2012). Immigrant students navigating Canadian schools: A longitudinal view. TESL Canada Journal/Revue Tes/ Du Canada, 143(29),142-146.

Harju, A. (2018). Children practising politics through spatial narratives. Children's Geographies, 16(2), 196-207.

Haskins, R., \& Tienda, M. (2011). Immigrant children: Introducing the issue. The Future of Children, (1), $1-16$.

Heywood, D., \& Peterson, S. S. (2007). Contributions of families' linguistic, social, and cultural capital to minority-language children's literacy: Parents', teachers', and principals' perspectives. The Canadian Modern Language Review, 63(4), 517-538.

Hornberger, N., \& Vaish, V. (2008). Multilingual language policy and school linguistic practice: Globalization and English-language teaching in India, Singapore and South Africa. Compare: A Journal of Comparative and International Education, 1(15), 1-16.

Isseri, S. (2016). The geographies of teaching and learning at a secondary school: Narratives of six high performing immigrants (Unpublished master's thesis). University of KwaZulu-Natal, South Africa.

Kamuangu, G. (2007). Learning and forgetting: The use of languages in the diaspora. The International Journal of Learning, 14(4), 49-52.

Kembhavi, G., \& Wirz, S. (2009). Engaging adolescents with disabilities in research. European Journal of Disability Research, 1(3), 286-296.

Kramp, M. K. (2004). Foundations for research: Methods of inquiry in education and the social sciences. Mahwah, USA: Lawrence Erlbaum.

Lalas, J., \& Valle, E. (2007). Social justice lenses and authentic student voices: Enhancing leadership for educational justice. Educational Leadership and Administration, 19, 75-102.

Lee, J. G. (2011). Understanding the process of educational assimilation for refugee and non-refugee immigrant students: A pilot study of a community college (Unpublished master's thesis). Graduate School of Vanderbilt University, USA.

Leonard, M. (2005). Children, childhood and social capital: Exploring the links. Sociology, 39(4), 605622.

Lumpkin, A. (2007). Caring teachers: The key to student learning. Retrieved from https://www.kuscholarworks.ku.edu/bitstream/handle/1808/11662

Maduray, K. (2014). The geographies of schooling spaces for immigrant children: Vulnerability, belonging, exclusion and power (Unpublished master's thesis). University of KwaZulu-Natal, South Africa.

Martin, A., Myers, N., \& Viseu, A. (2015). The politics of care in technoscience. Social Studies of Science, 45(5), 625-641.

Mashford-Scott, A., \& Church, A. (2011). Promoting children's agency in early childhood education. Retrieved from http://www.novitasroyal.org/

McCance, T. V., McKenna, H. P., \&. Boore, R. P. (2001). Exploring caring using narrative methodology: An analysis of the approach. Journal of Advanced Nursing, 33(3), 350-6.

McGregor, J. (2004, September). Studying spatiality. Paper presented at the British Educational Research Association Annual Conference, University of Manchester. Retrieved from http://www.leeds.ac.uk/educol/documents/00003785.htm 
McKamey, C. (2011). Restoring "caring" in education: Students' narratives of caring for and about. Narrative Works: Issues, Investigations and Interventions, 1(1), 78-94.

Naiditch, F. (2013). Cross the street to a new world. Kappan Magazine 94(6), 26-29.

Nansel, T. R., Overpeck, M., Pilla, R. S., Ruan, W. J., Simons-Morton, B., \& Scheidt, P. (2001). Bullying behaviours among US youth: Prevalence and association with psychosocial adjustment. JAMA 285(16), 2094-2100.

Noddings, N. (1992). The challenge to care in schools. New York, USA: Teachers College Press.

Phillion, J. (2002). Becoming a narrative inquirer in a multicultural landscape. Journal of Curriculum Studies, 34(5), 535-556.

Pinnegar, S., \& Danes, J. G. (2007). Locating narrative inquiry historically: Thematics in the turn to narrative. Thousand Oaks, USA: SAGE.

Punch, S., \& Tisdall, E. K. M. (2012). Exploring children's relationships across majority and minority worlds. Children's Geographies, 10(3), 249-264.

Ramirez, M. E. (2007) Resilience: A concept analysis. Nursing Forum, 42(2), 73-82.

Republic of South Africa. (1996). South African Schools Act, No. 84. Pretoria, South Africa: Government Printer.

Republic of South Africa. (1998). Refugees Act. Cape Town, South Africa: Government Printer.

Republic of South Africa. (2005). Children's Act. Cape Town, South Africa: Government Printer.

Schuster, L. (2012). Asylum-Seekers. Wiley-Blackwell Encyclopaedia of Globalization. Retrieved from http://www.onlinelibrary.wiley.com

Seror, J., Chen, L., \& Gunderson, L. (2005). Multiple perspectives on educationally resilient immigrant children. TESL Canada, 22(2), 55-74.

Sidhu, R., \& Taylor, S. (2012). Supporting refugee students in schools: What constitutes inclusive education? International Journal of Inclusive Education, 16(1) 39-56.

Tucker, F., \& Matthews, H. (2001). "They don't like girls hanging around there": Conflicts over recreational space in rural Northamptonshire. Area, 33(2), 161-168.

United Nations. (1989). Convention on the rights of the child. Retrieved from www.unicef.org/specialsession/under-18/guidetounss-may2002-eng.doc

Vandeyar, S. (2012). Immigrant students' shifting identifications in South African schools. International Journal of Educational Development, 32(2), 232-240.

Vandeyar, S., \& Vandeyar, T. (2012). Re-negotiating identities and reconciling cultural ambiguities: Socio-cultural experiences of Indian immigrant students in South African Schools. Journal of Social Science, 33(2), 155-167.

Van Ingen, C. V., \& Halas, F. (2006). Claiming space: Aboriginal students within school landscapes. Children's Geographies, 4(3), 379-398.

Wang, C., \& Burris, M. A. (1997). Photo-voice: Concept, methodology, and use for participatory needs assessment. Health Education and Behaviour, 24, 369-387.

Zhou, M., \& Kim, S. (2006) Community forces, social capital, and educational achievement: the case of supplementary education in the Chinese and Korean immigrant communities. Harvard Educational Review, 76(1), 1-29. 